\title{
Influence of tumour stage at breast cancer detection on survival in modern times: population based study in 173797 patients
}

\author{
Sepideh Saadatmand, ${ }^{1}$ Reini Bretveld, ${ }^{2}$ Sabine Siesling, ${ }^{2,3}$ Madeleine M A Tilanus-Linthorst ${ }^{1}$
}

1Department of Surgery, Erasmus University Medical Centre - Cancer Institute, 3075 EA, Rotterdam, Netherlands 2Department of Research, Netherlands Comprehensive Cancer Organization, 3511 DT, Utrecht, Netherlands

${ }^{3}$ Department of Health Technology and Services Research, MIRA Institute for Biomedical Technology and Technical Medicine, University of Twente, 7500 AE, Enschede Netherlands

Correspondence to: $M$ Tilanus-Linthorst

m.tilanus-linthorst@erasmusmc.nl

Additional material is published online only. To view please visit the journal online (http://dx.doi. org/10.1136/bmj.h4901)

Cite this as: $B M J$ 2015;351:h4901 doi: 10.1136/bmj.h4901

Accepted: 04 September 2015

\author{
ABSTRACT \\ OBJECTIVES \\ To assess the influence of stage at breast cancer \\ diagnosis, tumour biology, and treatment on survival \\ in contemporary times of better (neo-)adjuvant \\ systemic therapy. \\ DESIGN \\ Prospective nationwide population based study. \\ SETTING \\ Nationwide Netherlands Cancer Registry. \\ PARTICIPANTS
}

Female patients with primary breast cancer diagnosed between 1999 and 2012 ( $n=173797)$, subdivided into two time cohorts on the basis of breast cancer diagnosis: 1999-2005 ( $\mathrm{n}=80228)$ and 2006-12 $(n=93569)$.

\section{MAIN OUTCOME MEASURES}

Relative survival was compared between the two cohorts. Influence of traditional prognostic factors on overall mortality was analysed with Cox regression for each cohort separately.

RESULTS

Compared with 1999-2005, patients from 2006-12 had smaller $(\leq \mathrm{T} 165 \%(\mathrm{n}=60570)$ v $60 \%(\mathrm{n}=48031)$; $\mathrm{P}<0.001)$, more often lymph node negative (N0 68\% $(\mathrm{n}=63544)$ v 65\% $(\mathrm{n}=522238) ; \mathrm{P}<0.001)$ tumours, but they received more chemotherapy, hormonal therapy, and targeted therapy (neo-adjuvant/adjuvant systemic therapy $60 \%(n=56402) v 53 \%(n=42185) ; P<0.001)$. Median follow-up was 9.8 years for 1999-2005 and 3.9 years for 2006-12. The relative five year survival rate in

\section{WHAT IS ALREADY KNOWN ON THIS TOPIC}

Survival decreases with increasing tumour size and number of positive lymph nodes at detection of breast cancer, but data on these prognostic factors in patient cohorts after 2004 are scarce

(Neo-)adjuvant systemic therapies have improved significantly since 2004, and breast cancer survival rates have increased

To what extent stage at breast cancer detection, in terms of tumour size and number of positive lymph nodes, still determines survival in contemporary times is unknown

\section{WHAT THIS STUDY ADDS}

Relative survival of female breast cancer patients in a Dutch nationwide population based study of two time cohorts (1999-2005 and 2006-12) improved from 91\% to $96 \%$ at five years' follow up

Tumour size and nodal status still have a significant and major influence on overall mortality independent of age and tumour biology in the current era of more conservative surgery and newer systemic (neo-)adjuvant therapies

Early stage at detection is vital; surgery is crucial, and more conservative surgery is more favourable
2006-12 was $96 \%$, improved in all tumour and nodal stages compared with $1999-2005$, and $100 \%$ in tumours $\leq 1 \mathrm{~cm}$. In multivariable analyses adjusted for age and tumour type, overall mortality was decreased by surgery (especially breast conserving), radiotherapy, and systemic therapies. Mortality increased with progressing tumour size in both cohorts (2006-12 T1c v T1a: hazard ratio 1.54, 95\% confidence interval 1.33 to 1.78 ), but without a significant difference in invasive breast cancers until $1 \mathrm{~cm}$ (2006-12 T1b v T1a: hazard ratio 1.04, 0.88 to 1.22), and independently with progressing number of positive lymph nodes (2006-12 N1 v N0: 1.25, 1.17 to 1.32).

\section{CONCLUSIONS}

Tumour stage at diagnosis of breast cancer still influences overall survival significantly in the current era of effective systemic therapy. Diagnosis of breast cancer at an early tumour stage remains vital.

\section{Introduction}

Rates of survival with breast cancer have increased significantly all over the world in the past decades. ${ }^{1-3}$ In the United States, the five year relative survival rates for women with breast cancer have improved from approximately $75 \%$ in $1975-77$ to $90 \%$ in $2003-09 .{ }^{4}$ This improvement in survival can mainly be explained by an effect both of earlier diagnosis as a result of breast cancer screening and awareness and of better treatment options. ${ }^{56}$

The risk of metastases and death increases with both breast cancer size at detection and number of axillary lymph nodes involved. ${ }^{7-10}$ Screening aims to improve survival by decreasing the risk of metastases through early detection of breast cancer. In the Netherlands, the national breast screening programme with biennial mammography was implemented for all women aged 50-69 years in 1989, and in 1998 the programme was extended to age $71-75$ years. ${ }^{11}$

Next to tumour size and lymph node involvement, cancer related factors that influence survival are tumour grade, hormone receptor status, and human epidermal growth factor receptor 2 (HER2). ${ }^{8-12}$ Surgery, the cornerstone of breast cancer treatment, changed in the study period: to assess lymph node positivity, sentinel lymph node biopsy was first described in Dutch guidelines in $1999,{ }^{13}$ although regional implementation had already started. The proportion of patients with early stage breast cancer who had sentinel lymph node biopsy increased from approximately 9\% in 1998 to more than $70 \%$ in 2003. ${ }^{14}$ Recently, Mittendorf et al published data indicating that in patients with small breast cancers lymph node micro-metastases are not of any prognostic value. ${ }^{12}$ An explanation might be the increasing effectiveness of systemic therapy. 
In more recent years, (neo-)adjuvant systemic treatment for breast cancer has improved considerably and is applied more often. Improvements include the use of trastuzumab, which significantly increases both short term and long term prognosis in HER2 positive breast cancer patients. ${ }^{1516}$ Trastuzumab treatment was implemented in the Netherlands between 2005 and 2006. ${ }^{17} 18$ Moreover, a switch to more effective chemotherapy regimens has occurred. CMF (cyclophosphamide, methotrexate, 5 -fluorouracil) was prescribed to $90 \%$ of breast cancer patients receiving chemotherapy in 2000 and to almost none in $2005 .{ }^{19}$ It was gradually replaced by the more effective anthracyclines (4\% use in 2000 to $96 \%$ in 2005), which in turn were partly replaced by regimens containing taxane. ${ }^{19}$

Data published on the effect of screening and better treatment options on survival were based on cohorts of patients with breast cancer diagnosed in 2004 at the latest, and changes to more recent systemic therapy had not yet occurred. Traditional prognostic factors, such as tumour size and number of positive lymph nodes, may no longer predict survival in the current era of new systemic therapy; and if these factors do affect survival, the size of this effect is unknown. To quantify the effect of traditional prognostic factors, both long term and in the current era, we describe overall survival of female patients with breast cancer from two time cohorts (1999-2005 and 2006-12) in a nationwide population based study using data from the Netherlands Cancer Registry.

\section{Methods}

\section{Patient population}

We selected women diagnosed as having primary breast cancer between 1 January 1999 and 31 December 2012 from the Netherlands Cancer Registry. We excluded patients with a previous history of invasive cancer or lack of information on both clinical and pathological tumour size.

The Netherlands Cancer Registry is a nationwide prospective population based cancer registry in which all newly pathologically confirmed malignancies in the Netherlands are recorded. New malignancies are detected through the national pathology archive (PALGA), in which all pathological reports from Dutch hospitals are collected. Trained registrars from the cancer registry collect characteristics of patients and tumours and details of primary treatment directly from the patients' medical records. Vital status and date of death, if applicable, are verified by linkage to the municipal administration. Last date of linkage was 31 December 2013. Follow-up was complete for all women, except those who emigrated out of the Netherlands before that time.

\section{Patient involvement}

Regular contact of SSiesling and MMAT-L with members and representatives of the breast cancer patients' organisations the Netherlands Breast Cancer Association (NBCA), Pink Ribbon, and A Sister's Hope made the relevance of the outcome measures of this study clear for patients in making informed decisions about treatment and screening. Patients were not further involved in the design of the study. Patients will be informed of the results of this study through the websites of the NBCA, Netherlands Cancer Registry, and Dutch Cancer Society and information evenings of Pink Ribbon and a Sister's Hope.

\section{Procedures}

We subdivided patients into two time cohorts-1999-2005 and 2006-12-on the basis of their breast cancer diagnosis. We chose these cohorts because from 2005 onwards chemotherapy schemes used were changed, trastuzumab was implemented, ${ }^{17}$ and Dutch guidelines were more liberal on who should receive adjuvant treatment. ${ }^{18}$ We did analyses of the $1999-2005$ cohort to confirm long term effects of traditional prognostic factors on survival in earlier times in our Dutch population-wide cohort.

The following data were registered: date and age at breast cancer diagnosis, tumour characteristics, local and systemic therapy, vital status, second primary breast cancer, date of follow-up, and date of death. Local recurrence and occurrence of distant metastases were not registered by the cancer registry. Second primary breast cancer was defined as contralateral ductal carcinoma in situ or invasive epithelial breast cancer. ${ }^{20}$ For local breast therapy, we used the most extensive surgery performed within one year of diagnosis. Data on whether patients had axillary lymph node dissection was registered all years, but data on sentinel lymph node biopsy procedure was registered only from 2011. Staging of primary tumours was based on the American Joint Committee on Cancer pathological cancer staging classification, seventh edition. ${ }^{21}$ If pathological tumour size was missing, we used clinical stage based on imaging studies and clinical examination. Tumour stage was defined according to the greatest dimension of the largest tumour size (Tis=ductal carcinoma in situ, $\mathrm{T} 1 \mathrm{a}=\leq 0.5$ $\mathrm{cm}$ (including micro-invasion), $\mathrm{T} 1 \mathrm{~b}=>0.5 \mathrm{~cm}$ and $\leq 1 \mathrm{~cm}$, $\mathrm{T} 1 \mathrm{c}=>1 \mathrm{~cm}$ and $\leq 2 \mathrm{~cm}, \mathrm{~T} 2=>2 \mathrm{~cm}$ and $\leq 5 \mathrm{~cm}, \mathrm{~T} 3=>5 \mathrm{~cm}$, T4=any size with direct extension to chest wall and/or skin). Lymph node status was described according to the number of regional lymph nodes with pathologically proven metastasis. Determination of lymph node positivity included results of sentinel lymph node biopsy. Lymph nodes with only isolated tumour cells were defined lymph node negative $(\mathrm{NO}=$ no pathologically proven positive lymph nodes, N1=1-3 positive, $\mathrm{N} 2=4-9$ positive, $\mathrm{N} 3=\geq 10$ positive). Grading of tumours was based on the modified Bloom and Richardson grading system. ${ }^{22}$ Patients were considered oestrogen positive and progesterone positive in case of more than $10 \%$ nuclear staining. Hormone receptor status was registered from 2005 and onward, and HER2 status was registered in the Netherlands Cancer Registry from 2006 onward.

\section{Statistical analysis}

We used Pearson's $\chi^{2}$ tests to calculate differences in stage distributions, lymph node status, and tumour 
characteristics between the two time cohorts. We assessed differences in age distribution at breast cancer diagnosis as a continuous variable with the Mann-Whitney $U$ test and also assessed them with a $\chi^{2}$ test after categorical subdivision.

We defined overall survival as time from diagnosis of breast cancer to death from any cause. ${ }^{23}$ We defined relative survival as the relative excess risk of death or the observed survival of our study population divided by the expected survival of the corresponding general population by sex, age, and year of diagnosis. ${ }^{24}$ We calculated relative survival by using the Ederer II method. We used Dutch national life tables from the Central Bureau of Statistics (CBS) to estimate expected survival in the general population. We estimated relative five year survival rates and plotted relative survival curves stratified for tumour stage and nodal stage. Women were censored at date of last follow-up. As the follow-up of women in the two time cohorts differed considerably, all analyses were stratified for time period of breast cancer detection.

We developed Cox univariable and multivariable proportional hazard models for overall mortality for invasive breast cancers to estimate hazard ratios with 95\% confidence intervals. We used Cox regression univariable and multivariable analyses only for invasive breast cancers, because hormone receptor and HER2 status are not routinely determined for ductal carcinoma in situ tumours in the Netherlands and including them in analyses would make inclusion of these factors into multivariable analyses impossible. To compare differences in hazard rates between the two time cohorts, we did additional analyses and limited maximum follow-up time for both cohorts to five years. We did not include hormone receptor and HER2 status, as these were unavailable in the oldest cohort; to compare hazard rates between the two time cohorts, we built a similar model but ductal carcinoma in situ was included. In multivariable analyses, we included all relevant clinicopathological variables and variables with a $P$ value below 0.05 in univariable analyses. We found the assumption of proportional hazards to be valid by graphically plotting the log-log survival curves. We considered a two sided P value of 0.05 or less to be statistically significant. We analysed missing values as a separate unknown group within the same variable. We present hazard ratios with corresponding 95\% confidence intervals and used the rule of four to ensure that the rounding error was less than $1.3 \%$ for all ratios. ${ }^{25}$ We used SPSS Statistics for Windows (version 20.0) for statistical analyses and SAS (version 9.4) for relative survival.

\section{Results}

Characteristics of patients and tumours

In the Netherlands, 173797 female patients were diagnosed as having primary breast cancer with known tumour stage between 1999 and 2012: 80228 (46\%) from 1999 to 2005 and 93569 (54\%) from 2006 to 2012. Tumour size was defined clinically, instead of pathologically, for 11929 (6.9\%). Median age at diagnosis was
59.3 years for the cohort of 1999-2005 and 60.0 years for the 2006-12 cohort; continuous age distribution was comparable $(\mathrm{P}=0.169)$. However, when we categorised age at breast cancer diagnosis (supplementary figure), we found a significant difference between the distribution in age categories of 1999-2005 and 2006-12 $(\mathrm{P}<0.001)$. Compared with 1999-2005, tumours diagnosed in 2006-12 were smaller ( $\leq \mathrm{T} 165 \%$ (60 570/93569) versus 60\% (48031/80 228); $\mathrm{P}<0.001)$ and were more often lymph node negative (N0 68\% (63544/93569) versus 65\% (52238/80 228); $\mathrm{P}<0.001)$ and low grade (invasive cancers grade $121 \%$ (17334/93569) versus $16 \%$ (11939/80 228); $\mathrm{P}<0.001)$. Patients recently diagnosed as having breast cancer more often had breast conserving therapy $(54 \% \quad(50313 / 93569)$ versus $48 \%$ (38638/80228); $\mathrm{P}<0.001)$, whereas axillary node dissection was performed less often $(\mathrm{P}<0.001)$. Uptake of radiotherapy and systemic therapy was increased ( $\mathrm{P}<0.001)$ : hormonal therapy by $10 \%$, chemotherapy by $7 \%$, targeted therapy (mainly trastuzumab) by $7 \%$, and the combination by $7 \%$. Hormone receptor status was available for invasive breast cancers in the most recent cohort of 2006-12 only. Oestrogen receptor was negative in $13876(17 \%)$, positive in 67993 (82\%), and unknown in $1352(2 \%)$ of 83221 invasive breast cancers diagnosed in 2006-12. Progesterone was negative in 26268 (32\%), positive in 53557 (64\%), and unknown in 3396 (4\%). HER2 status was negative in $67418(81 \%)$, positive in 10899 (13\%), and unknown in 4904 (6\%). Table 1 shows further results.

\section{Relative and overall survival}

Median follow-up was 9.8 (range 0-15) years for the first cohort (1999-2005) and 3.9 (0-8) years for the second cohort (2006-12). During follow-up, 27924 events occurred in the first cohort and 11177 in the second cohort. We plotted relative survival curves for both tumour stage (fig 1) and nodal stage (fig 2). Compared with 1999-2005, five year relative survival rates and overall survival rates were higher for the 2006-12 cohort for all tumour and nodal stages (table 2). Relative survival of ductal carcinoma in situ was 100\% after 15 years for the $1999-2005$ cohort and $101 \%$ after 8 years for the 2006-12 cohort. Relative survival decreased with increasing tumour and nodal stages, except for T1b versus T1a (1999-2005 100\% v 99\%; $2006-12101 \%$ v 100\%). Relative survival in the 19992005 cohort did not decrease after nine years for all tumour sizes T1c or smaller and after 13 years for tumours T2 or larger. In the 2006-12 cohort, no decrease in relative survival was seen in tumour sizes $\mathrm{T} 2$ or smaller after six years and for tumour sizes larger than $\mathrm{T} 2$ after seven years.

\section{Prognostic factors: cohort 1999-2005}

We did Cox regression univariable and multivariable analyses only for invasive breast cancers. Patients with breast surgery classified as "other" were excluded from analyses, owing to the small numbers ( $n=93$ in all patients with invasive breast cancer in both time cohorts) and heterogeneity of this group. Of 73245 


\begin{tabular}{|c|c|c|c|c|}
\hline Characteristic/treatment & $1999-2005(n=80228)$ & $2006-12(n=93569)$ & Total $(n=173797)$ & Pvalue* \\
\hline Median (range) age at diagnosis, years & $59.3(17.1-100.4)$ & $60.0(18.9-103.1)$ & $59.7(17.1-103.1)$ & 0.169 \\
\hline Second primary breast cancer & $5539(7)$ & $3733(4)$ & $9272(5)$ & $<0.001$ \\
\hline \multicolumn{5}{|l|}{ Pathological tumour categoryt: } \\
\hline Ductal carcinoma in situ & $6920(9)$ & $10348(11)$ & $17268(10)$ & \multirow{7}{*}{$<0.001$} \\
\hline T1a & $2398(3)$ & $3846(4)$ & $6244(4)$ & \\
\hline T1b & $9599(12)$ & $12213(13)$ & $21812(13)$ & \\
\hline T1c & $29114(36)$ & $34163(37)$ & $63277(36)$ & \\
\hline $\mathrm{T} 2$ & $26624(33)$ & $27946(30)$ & $54570(31)$ & \\
\hline T3 & 2711 (3) & $3213(3)$ & $5924(3)$ & \\
\hline T4 & $2862(4)$ & $1840(2)$ & $4702(3)$ & \\
\hline \multicolumn{5}{|l|}{ Pathological node category: } \\
\hline NO & $52238(65)$ & $63544(68)$ & $115782(67)$ & \multirow{4}{*}{$<0.001$} \\
\hline N1 & $19012(24)$ & $21901(23)$ & $40913(24)$ & \\
\hline N2 & $5985(8)$ & $5400(6)$ & $11385(7)$ & \\
\hline N3 & $2993(4)$ & $2724(3)$ & $5717(3)$ & \\
\hline \multicolumn{5}{|l|}{ B\&R grade, DCIS only: } \\
\hline Grade 1 & $986(14)$ & $1667(16)$ & $2653(15)$ & \multirow{4}{*}{$<0.001$} \\
\hline Grade 2 & $1798(26)$ & $3162(31)$ & $4960(29)$ & \\
\hline Grade 3 (including anaplastic) & $2863(41)$ & $4842(47)$ & $7705(45)$ & \\
\hline Unknown & $1273(18)$ & $677(7)$ & 1950 (11) & \\
\hline \multicolumn{5}{|l|}{ B\&R grade, invasive cancers only: } \\
\hline Grade 1 & $11939(16)$ & $17334(21)$ & $29273(19)$ & \multirow{4}{*}{$<0.001$} \\
\hline Grade 2 & $26923(37)$ & $32672(39)$ & $59595(38)$ & \\
\hline Grade 3 (including anaplastic) & $21119(29)$ & $22269(27)$ & $43388(28)$ & \\
\hline Unknown & $13327(18)$ & $10946(13)$ & $24273(16)$ & \\
\hline \multicolumn{5}{|l|}{ Morphology, invasive cancers only: } \\
\hline Ductal carcinoma or ductal mixed type & $56144(77)$ & $66124(80)$ & $122268(78)$ & \multirow{3}{*}{$<0.001$} \\
\hline Lobular carcinoma & $8133(11)$ & $9133(11)$ & $17003(11)$ & \\
\hline Other & $9031(12)$ & 7964 (10) & $17266(11)$ & \\
\hline \multicolumn{5}{|l|}{ Breast surgery: } \\
\hline No surgery & $3319(4)$ & $4877(5)$ & $8196(5)$ & \multirow{4}{*}{$<0.001$} \\
\hline Breast conserving therapy & $38638(48)$ & $50313(54)$ & $88951(51)$ & \\
\hline Mastectomy & $38040(47)$ & $38307(41)$ & $76347(44)$ & \\
\hline Other & $231(0)$ & $72(0)$ & $303(0)$ & \\
\hline Axillary lymph node dissection & $45438(57)$ & $31021(33)$ & $76459(44)$ & $<0.001$ \\
\hline Systemic therapy $¥$ & $42185(53)$ & $56402(60)$ & $98587(57)$ & $<0.001$ \\
\hline Chemotherapy & $24029(30)$ & $34819(37)$ & $58848(34)$ & $<0.001$ \\
\hline Hormonal therapy & $31320(39)$ & 45357 (49) & $76677(44)$ & $<0.001$ \\
\hline Targeted therapy & $725(1)$ & $7411(8)$ & $8136(5)$ & $<0.001$ \\
\hline Radiotherapy & $46925(59)$ & $59100(63)$ & $106025(61)$ & $<0.001$ \\
\hline
\end{tabular}

All percentages were calculated vertically. Total of percentages may not equal $100 \%$ owing to rounding. Missing values were analysed as separate unknown group within same variable.

$\mathrm{B} \& \mathrm{R}=\mathrm{Bloom}$ and Richardson; DCIS=ductal carcinoma in situ; $\mathrm{NO}=$ no pathologically assessed regional lymph nodes with metastasis/isolated tumour cells; $\mathrm{N} 1=$ metastasis in $1-3$ regional lymph nodes; $\mathrm{N} 2=$ metastasis in 4-9 ipsilateral regional lymph nodes; $\mathrm{N} 3=$ metastasis in $\geq 10$ regional lymph nodes; $\mathrm{T} 1 \mathrm{a}=\leq 0.5 \mathrm{~cm}$ (including micro-invasion); $\mathrm{T1b} \Rightarrow 0.5 \mathrm{~cm}$ and $\leq 1 \mathrm{~cm} ; \mathrm{T} 1 \mathrm{c} \Rightarrow 1 \mathrm{~cm}$ and $\leq 2$ $\mathrm{cm} ; \mathrm{T} 2 \Rightarrow 2 \mathrm{~cm}$ and $\leq 5 \mathrm{~cm} ; \mathrm{T} 3 \Rightarrow 5 \mathrm{~cm} ; \mathrm{T} 4=$ any size with direct extension to chest wall and $/$ or $\mathrm{kkin}$.

*Two sided P value for difference between two time cohorts; differences in age distribution at diagnosis were calculated from Mann-Whitney $U$ test; all other differences were obtained from $\chi^{2}$ test. tDifference in tumour stage distribution between two time cohorts excluding DICS was also $\mathrm{P}<0.001$.

\#Includes chemotherapy, hormonal therapy, and all targeted therapy (mainly trastuzumab).

patients diagnosed as having invasive breast cancer between 1999 and 2005, 26717 (37\%) died during follow-up. With univariable and multivariable Cox regression analyses, we assessed influence on overall mortality of age, second primary breast cancer, tumour and nodal stage, grade, morphology, breast surgery, axillary lymph node dissection, chemotherapy, hormonal therapy, targeted therapy, and radiotherapy. Cox regression univariable and multivariable analyses showed that after correction for the above factors, higher tumour stage and lymph node positivity increased overall mortality (table 3 ).

\section{Prognostic factors: cohort 2006-12}

In the 2006-12 cohort, 10778 (13\%) of 83191 patients with invasive breast cancer died during follow-up. In Cox regression univariable analyses, all clinicopathological variables were significantly associated with overall mortality (table 4). In multivariable analysis, we adjusted for age, tumour and nodal stage, grade, morphology, hormone receptor and HER2 status, breast surgery, axillary lymph node dissection, chemotherapy, hormonal therapy, targeted therapy, radiotherapy, and second primary breast cancer. Tumour stage and nodal stage were both significantly 

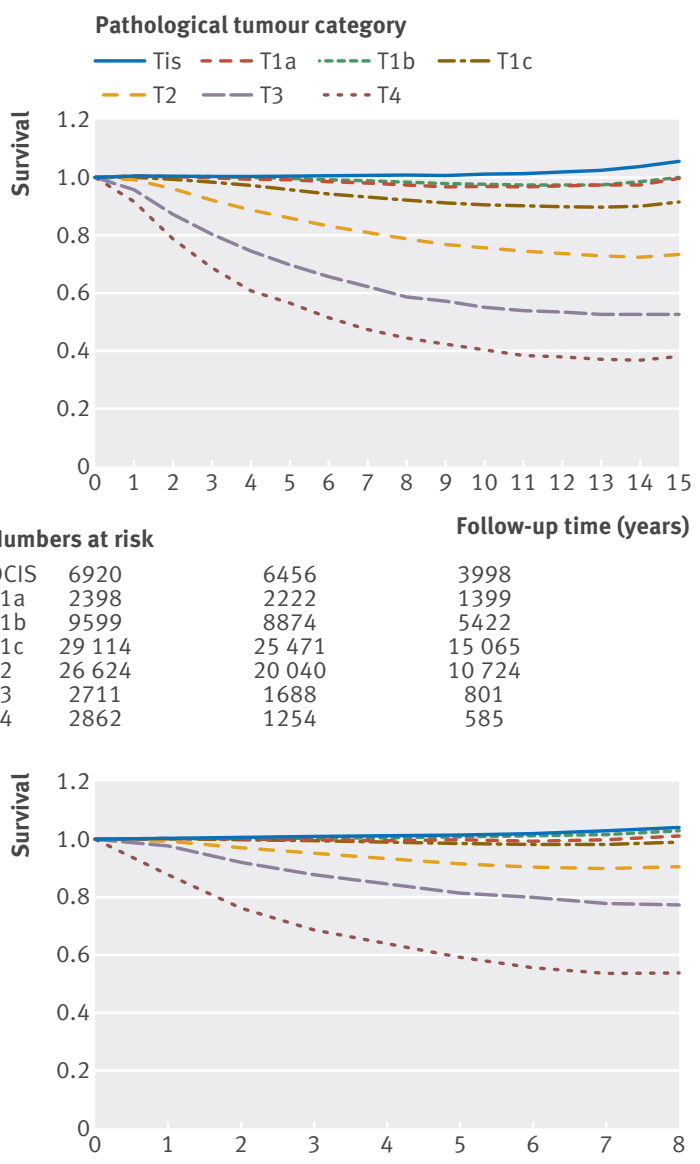

Numbers at risk

$\begin{array}{lcccc}\text { DCIS } & 10348 & 8386 & 4939 & 2278 \\ \text { T1a } & 3846 & 3093 & 1755 & 778 \\ \text { T1b } & 12213 & 9977 & 6217 & 2906 \\ \text { T1c } & 34163 & 28044 & 17399 & 8101 \\ \text { T2 } & 27946 & 21948 & 13130 & 5861 \\ \text { T3 } & 3213 & 2355 & 1269 & 535 \\ \text { T4 } & 1840 & 1061 & 516 & 184\end{array}$

Fig 1 | Tumour stage specific relative survival of breast cancer patients in Netherlands Cancer Registry diagnosed as having breast cancer in 1999-2005 (top) and 2006-12 (bottom). Relative survival was defined as observed survival divided by expected survival of corresponding general population, matched by sex, age, and year of diagnosis. Tis=ductal carcinoma in situ; $T 1 a=\leq 0.5 \mathrm{~cm}$ (including micro-invasion); $\mathrm{T} 1 \mathrm{~b}=>0.5 \mathrm{~cm}$ and $\leq 1 \mathrm{~cm}$; T1c $=>1$ $\mathrm{cm}$ and $\leq 2 \mathrm{~cm} ; \mathrm{T} 2=>2 \mathrm{~cm}$ and $\leq 5 \mathrm{~cm} ; \mathrm{T} 3=>5 \mathrm{~cm} ; \mathrm{T} 4=$ any size with direct extension to chest wall and/or skin

associated with overall mortality, although tumour size had a significant influence only when larger than $1 \mathrm{~cm}$ (T1b $v$ T1a: hazard ratio 1.04, 95\% confidence interval 0.88 to $1.22 ; \mathrm{P}=0.677$ ). Positive hormone receptors lowered the hazard rate of death by $20-30 \%$ $(\mathrm{P}<0.001)$, in contrast to positive HER2 status which lost significance in multivariable analyses (hazard ratio $1.00,0.93$ to $1.08 ; \mathrm{P}=0.933$ ). Axillary lymph node dissection increased the hazard rate (hazard ratio 1.29, 1.21 to 1.38 ; $\mathrm{P}<0.001)$, and breast conserving therapy decreased it $(0.87,0.81$ to $0.93 ; \mathrm{P}<0.001)$. Treatment with chemotherapy, hormonal therapy, targeted therapy, and radiotherapy all led to lower hazard rates $(\mathrm{P}<0.001)$. Contrary to univariable analysis, second
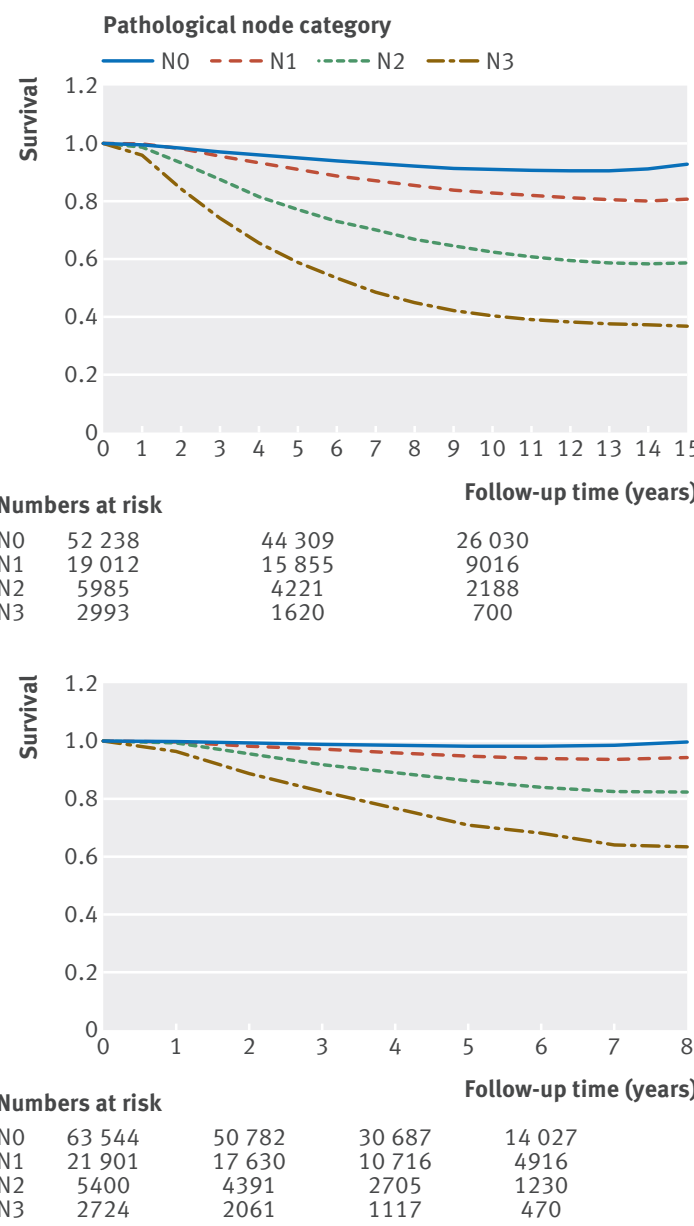

Fig 2 | Nodal stage specific relative survival of breast cancer patients in Netherlands Cancer Registry diagnosed as having breast cancer in 1999-2005 (top) and 2006-12 (bottom). Relative survival was defined as observed survival divided by expected survival of corresponding general population, matched by sex, age, and year of diagnosis. $\mathrm{N} 0=$ no pathologically assessed regional lymph nodes with metastasis/isolated tumour cells; $\mathrm{N} 1=$ metastasis in 1-3 regional lymph nodes; $\mathrm{N} 2=$ metastasis in 4-9 regional lymph nodes; $N 3=$ metastasis in $\geq 10$ regional lymph nodes

primary breast cancer had no effect on overall mortality in multivariable analysis (hazard ratio 1.01, 0.93 to $1.11 ; \mathrm{P}=0.762$ ).

Prognostic factors: comparison between 1999-2005 and 2006-12 cohorts

To compare the hazard rates of the two time cohorts, we also did multivariable Cox regression analyses restricting follow-up time to a maximum of five years (supplementary table). Hazard rates for overall mortality were lower for all tumour stages and lymph node stages in 2006-12 compared with 1999-2005. Hazard rates for ductal carcinoma in situ were significantly lower than the reference category T1a in both time cohorts.

\section{Discussion}

In this Dutch population-wide prospective cohort study, we estimated the influence of well established prognostic factors in 173797 female patients with 


\begin{tabular}{|c|c|c|c|c|}
\hline \multirow[b]{2}{*}{ Characteristic } & \multicolumn{2}{|c|}{ Overall survival* (\%) } & \multicolumn{2}{|c|}{ Relative survivalt (\%) } \\
\hline & 1999-2005 & $2006-12$ & 1999-2005 & 2006-12 \\
\hline All patients & 83 & 88 & 91 & 96 \\
\hline \multicolumn{5}{|l|}{ Tumour stage: } \\
\hline DCIS & 94 & 96 & 100 & 101 \\
\hline T1a & 93 & 95 & 99 & 100 \\
\hline $\mathrm{T} 1 \mathrm{~b}$ & 93 & 95 & 100 & 101 \\
\hline T1c & 88 & 91 & 96 & 98 \\
\hline T2 & 76 & 82 & 86 & 92 \\
\hline T3 & 63 & 73 & 70 & 81 \\
\hline T4 & 44 & 45 & 57 & 59 \\
\hline \multicolumn{5}{|l|}{ Nodal stage: } \\
\hline No & 85 & 90 & 95 & 98 \\
\hline N1 & 84 & 88 & 91 & 95 \\
\hline N2 & 71 & 81 & 77 & 86 \\
\hline N3 & 55 & 66 & 59 & 71 \\
\hline \multicolumn{5}{|c|}{ Age at breast cancer diagnosis: } \\
\hline$<50$ years & 89 & 94 & 90 & 95 \\
\hline $50-75$ years & 88 & 93 & 94 & 97 \\
\hline$>75$ years & 51 & 56 & 83 & 91 \\
\hline
\end{tabular}

DCIS=ductal carcinoma in situ.

*Time from breast cancer diagnosis to death from any cause.

tobserved survival divided by expected survival of corresponding general population, matched by sex, age, and year of diagnosis; calculated using Ederer II method. Women were censored at date of last follow-up.

primary breast cancer in two time cohorts: $1999-2005$ and 2006-12. Notably, we observed a $17 \%$ increase in diagnosis of breast cancer between the two time periods. Part of this might be explained by the ageing society, as increasing age is a major risk factor for breast cancer. Between 1999-2005 and 2006-12, the Dutch female population grew by approximately $2.7 \%$ but the female population aged 60-69 years grew by approximately $23 \% .{ }^{26}$ Median age at diagnosis of breast cancer was around 59 years, with a peak around the menopause (age cohort 50-59 years). Tumours diagnosed in the most recent cohort were smaller, more often lymph node negative, and more often low grade than tumours from the first time period. Five year relative survival rates improved in the recent cohort in all tumour stages, to $100 \%$ in all tumours $1 \mathrm{~cm}$ or smaller and to $98 \%$ for tumours between $1 \mathrm{~cm}$ and $2 \mathrm{~cm}$, and improved increasingly with larger tumour size. Relative survival increased especially in women aged over 75 years.

In univariable and multivariable analyses, both tumour stage and lymph node status had a significant influence on overall survival in both cohorts $(\mathrm{P}<0.001)$. The importance of early detection is dual-with increasing tumour size, lymph node positivity also increases. ${ }^{27}$ We determined the influence of stage corrected for both tumour biology and treatment. We found no difference in hazard rate for breast cancers sized $1 \mathrm{~cm}$ or smaller, neither with long term follow-up nor in recent times (2006-12 T1b $v$ T1a, $\mathrm{P}=0.677)$. When node negative, these patients do not regularly get adjuvant therapy in the Netherlands even when oestrogen receptor negative. With 100\% five year relative survival rates, simplifying the next edition of the pathological tumour classification by combining T1a and T1b into one extremely favourable category seems justified.

Patients with breast cancer diagnosed between 2006 and 2012 had breast conserving therapy more often and axillary lymph node dissection less often $(\mathrm{P}<0.001)$, owing to the increasing use of sentinel lymph node biopsies over the years. ${ }^{14}$ Although tumour stage was more favourable in patients in the 2006-12 cohort, uptake of all forms of (neo-)adjuvant systemic therapy was increased $(\mathrm{P}<0.001)$, mainly due to the extended indication in Dutch guidelines from 2005 onward, ${ }^{18}$ as well as possibly to down staging of tumours treated with neo-adjuvant therapy.

Surgery is of prime importance for survival, and breast conserving therapy conferred a favourable survival compared with mastectomy despite correction for stage, age, and adjuvant therapies (hazard ratio $0.87,0.81$ to 0.93 ; $\mathrm{P}<0.001)$. In the $2006-12$ cohort, axillary lymph node dissection, advised only for patients with positive lymph nodes confirmed by sentinel node

Table 3 | Cox univariable and multivariable analyses of clinicopathological variables for overall mortality in patients with invasive breast cancer in Netherlands Cancer Registry, 1999-2005

\begin{tabular}{|c|c|c|c|c|c|}
\hline \multirow[b]{2}{*}{ Clinicopathological variables } & \multicolumn{2}{|l|}{ Univariable analyses } & \multicolumn{3}{|c|}{ Multivariable analyses* } \\
\hline & Hazard ratio $(95 \% \mathrm{Cl})$ & Pvalue & No & Hazard ratio $(95 \% \mathrm{Cl})$ & P value \\
\hline \multicolumn{6}{|l|}{ Pathological tumour category: } \\
\hline T1a & Reference & & 2393 & Reference & \\
\hline $\mathrm{T} 1 \mathrm{~b}$ & 1.07 (0.97 to 1.18) & 0.195 & 9589 & 1.09 (0.99 to 1.20$)$ & 0.098 \\
\hline T1c & $1.50(1.37$ to 1.64$)$ & $<0.001$ & 29100 & 1.40 (1.27 to 1.53$)$ & $<0.001$ \\
\hline $\mathrm{T} 2$ & 2.74 (2.50 to 3.00$)$ & $<0.001$ & 26597 & 1.91 (1.74 to 2.10$)$ & $<0.001$ \\
\hline T3 & $4.2(3.76$ to 4.6$)$ & $<0.001$ & 2710 & 2.60 (2.34 to 2.89$)$ & $<0.001$ \\
\hline T4 & $7.6(6.9$ to 8.4$)$ & $<0.001$ & 2856 & 2.77 (2.50 to 3.07$)$ & $<0.001$ \\
\hline \multicolumn{6}{|l|}{ Pathological node category: } \\
\hline NO & Reference & & 45280 & Reference & \\
\hline N1 & 1.04 (1.01 to 1.07$)$ & 0.018 & 18993 & 1.35 (1.30 to 1.39$)$ & $<0.001$ \\
\hline N2 & 1.78 (1.72 to 1.85$)$ & $<0.001$ & 5981 & 2.19 (2.08 to 2.30$)$ & $<0.001$ \\
\hline N3 & $3.02(2.89$ to 3.17$)$ & $<0.001$ & 2991 & 3.48 (3.28 to 3.69$)$ & $<0.001$ \\
\hline
\end{tabular}

*Corrected for age, tumour grade and morphology, breast surgery, axillary lymph node dissection, chemotherapy, hormonal therapy, targeted therapy, radiotherapy, and second primary breast cancer. 
Table 4 | Cox univariable and multivariable analyses of clinicopathological variables for overall mortality in patients with invasive breast cancer in Netherlands Cancer Registry, 2006-12

\begin{tabular}{|c|c|c|c|c|c|}
\hline \multirow[b]{2}{*}{ Clinicopathological variables } & \multicolumn{2}{|l|}{ Univariable analyses } & \multicolumn{3}{|c|}{ Multivariable analyses* } \\
\hline & Hazard ratio $(95 \% \mathrm{Cl})$ & Pvalue & No & Hazard ratio $(95 \% \mathrm{Cl})$ & $P$ value \\
\hline Age at diagnosis in years & 1.07 (1.07 to 1.07$)$ & $<0.001$ & 83191 & 1.04 (1.04 to 1.05$)$ & $<0.001$ \\
\hline \multicolumn{6}{|l|}{ Pathological tumour category: } \\
\hline T1a & Reference & & 3840 & Reference & \\
\hline T1b & 0.93 (0.79 to 1.09 ) & 0.339 & 12207 & 1.04 (0.88 to 1.22$)$ & 0.677 \\
\hline T1c & 1.61 (1.39 to 1.85$)$ & $<0.001$ & 34156 & $1.54(1.33$ to 1.78$)$ & $<0.001$ \\
\hline T2 & 3.53 (3.07 to 4.1$)$ & $<0.001$ & 27937 & 2.17 (1.87 to 2.52$)$ & $<0.001$ \\
\hline T3 & $5.6(4.8$ to 6.6$)$ & $<0.001$ & 3212 & 2.78 (2.36 to 3.27 ) & $<0.001$ \\
\hline T4 & $14.6(12.6$ to 17.1$)$ & $<0.001$ & 1839 & $3.32(2.83$ to 3.90$)$ & $<0.001$ \\
\hline \multicolumn{6}{|l|}{ Pathological node category: } \\
\hline NO & Reference & & 53223 & Reference & \\
\hline N1 & 1.01 (0.96 to 1.06$)$ & 0.734 & 21851 & 1.25 (1.17 to 1.32$)$ & $<0.001$ \\
\hline N2 & 1.66 (1.56 to 1.78$)$ & $<0.001$ & 5396 & 2.36 (2.16 to 2.58$)$ & $<0.001$ \\
\hline N3 & 3.19 (2.97 to 3.41$)$ & $<0.001$ & 2721 & $4.0(3.66$ to 4.4$)$ & $<0.001$ \\
\hline \multicolumn{6}{|l|}{ Bloom and Richardson grade: } \\
\hline Grade 1 & Reference & & 17327 & Reference & \\
\hline Grade 2 & $1.42(1.33$ to 1.53$)$ & $<0.001$ & 32662 & $1.18(1.10$ to 1.27$)$ & $<0.001$ \\
\hline Grade 3 (including anaplastic) & 2.49 (2.33 to 2.67$)$ & $<0.001$ & 22263 & 1.69 (1.56 to 1.82$)$ & $<0.001$ \\
\hline Unknown & $6.2(5.8$ to 6.6$)$ & $<0.001$ & 10939 & 1.68 (1.54 to 1.83$)$ & $<0.001$ \\
\hline \multicolumn{6}{|l|}{ Morphology: } \\
\hline Ductal carcinoma or ductal mixed & Reference & & 66104 & Reference & \\
\hline Lobular carcinoma & $1.20(1.13$ to 1.27$)$ & $<0.001$ & 9127 & 0.91 (0.86 to 0.97$)$ & 0.003 \\
\hline Other & $1.64(1.55$ to 1.73$)$ & $<0.001$ & 7960 & $0.94(0.89$ to 1.00$)$ & 0.040 \\
\hline \multicolumn{6}{|l|}{ Oestrogen receptor status: } \\
\hline Negative & Reference & & 13873 & Reference & \\
\hline Positive & 0.55 (0.53 to 0.58$)$ & $<0.001$ & 67967 & $0.71(0.66$ to 0.77$)$ & $<0.001$ \\
\hline Unknown & 1.21 (1.08 to 1.37$)$ & 0.001 & 1351 & 1.00 (0.85 to 1.18$)$ & 0.972 \\
\hline \multicolumn{6}{|l|}{ Progesterone receptor status: } \\
\hline Negative & Reference & & 26261 & Reference & \\
\hline Positive & 0.58 (0.56 to 0.60$)$ & $<0.001$ & 53535 & $0.81(0.77$ to 0.85$)$ & $<0.001$ \\
\hline Unknown & 0.93 (0.85 to 1.01$)$ & 0.069 & 3395 & 0.81 (0.72 to 0.90$)$ & $<0.001$ \\
\hline \multicolumn{6}{|l|}{ HER2 status: } \\
\hline Negative & Reference & & 67393 & Reference & \\
\hline Positive & $1.06(1.00$ to 1.12$)$ & 0.047 & 10897 & 1.00 (0.93 to 1.08$)$ & 0.933 \\
\hline Unknown/inconclusive & 2.88 (2.73 to 3.04$)$ & $<0.001$ & 4901 & 0.94 (0.88 to 1.00$)$ & 0.045 \\
\hline \multicolumn{6}{|l|}{ Breast surgery: } \\
\hline Mastectomy & Reference & & 34421 & Reference & \\
\hline Breast conserving therapy & $0.389(0.372$ to 0.41$)$ & $<0.001$ & 44117 & 0.87 (0.81 to 0.93$)$ & $<0.001$ \\
\hline No surgery & $7.6(7.2$ to 7.9$)$ & $<0.001$ & 4653 & 4.1 (3.78 to 4.5$)$ & $<0.001$ \\
\hline \multicolumn{6}{|l|}{ Axillary lymph node dissection: } \\
\hline No & Reference & & 52353 & Reference & \\
\hline Yes & 1.18 (1.14 to 1.23$)$ & $<0.001$ & 30838 & 1.29 (1.21 to 1.38$)$ & $<0.001$ \\
\hline \multicolumn{6}{|l|}{ Chemotherapy: } \\
\hline No & Reference & & 48417 & Reference & \\
\hline Yes & 0.52 (0.50 to 0.54$)$ & $<0.001$ & 34774 & 0.86 (0.80 to 0.92$)$ & $<0.001$ \\
\hline \multicolumn{6}{|l|}{ Hormonal therapy: } \\
\hline No & Reference & & 37931 & Reference & \\
\hline Yes & $1.21(1.17$ to 1.26$)$ & $<0.001$ & 45260 & 0.64 (0.61 to 0.68$)$ & $<0.001$ \\
\hline \multicolumn{6}{|l|}{ Targeted therapy: } \\
\hline No & Reference & & 75797 & Reference & \\
\hline Yes & 0.55 (0.51 to 0.60$)$ & $<0.001$ & 7394 & 0.58 (0.52 to 0.65$)$ & $<0.001$ \\
\hline \multicolumn{6}{|l|}{ Radiotherapy: } \\
\hline No & Reference & & 29569 & Reference & \\
\hline Yes & 0.353 (0.340 to 0.367$)$ & $<0.001$ & 53622 & 0.69 (0.64 to 0.73$)$ & $<0.001$ \\
\hline \multicolumn{6}{|l|}{ Second primary breast cancer: } \\
\hline No & Reference & & 79889 & Reference & \\
\hline Yes & 1.12 (1.03 to 1.23$)$ & 0.010 & 3302 & 1.01 (0.93 to 1.11$)$ & 0.762 \\
\hline
\end{tabular}

*Adjusted for age, tumour and nodal stage, grade, morphology, hormone receptor and HER2 status, breast surgery, axillary lymph node dissection, chemotherapy, hormonal therapy, targeted therapy, radiotherapy, and second primary breast cancer. 
biopsy or cytology, decreased overall survival in multivariable analysis (hazard ratio 1.29, 1.21 to 1.38; $\mathrm{P}<0.001)$.

In multivariable analyses, chemotherapy decreased the hazard of death by approximately $14 \%$ in the 2006 12 cohort. HER2 status was known for the 2006-12 cohort, but after adjustment for targeted therapies such as trastuzumab, HER2 positive status was no longer significantly associated with overall survival. Apparently, trastuzumab is so effective that, with its current use in tumours larger than $1 \mathrm{~cm}$, the effect of HER2 positivity on survival becomes negligible. The group with unknown HER2 status contained a large number of patients with inconclusive HER2 status, who might well be HER2 positive but who did not all receive targeted therapy. This group had significantly higher hazard rates, which endorses the necessity of targeted therapy in HER2 positive patients.

\section{Comparison with other studies}

Owing to the relatively favourable survival rates of patients with breast cancer, long follow-up and large groups of patients are needed to provide sufficient power to detect differences in overall survival. A recent Lancet publication with global data showed age standardised net survival with breast cancer of $80 \%$ or more in 34 countries and an increase worldwide but had no data on factors influencing it. ${ }^{1}$ Our more recent results from 2006-12 even indicated a five year relative survival rate of $96 \%$. Another recent study compared breast cancer recurrence and outcome patterns in 3589 patients treated from 1986 to 1992 matched one to one with patients from 2004-08. ${ }^{3}$ The authors describe a lower hazard rate of breast cancer relapse and a lower hazard rate of death in the later time period, but similar outcome patterns by oestrogen receptor and HER2 receptor status. Their study was not designed to identify current prognostic factors. This study is difficult to compare with ours, as it differs with respect to the timeframes chosen for the cohorts, the matched design, and the much lower number of patients. Another study by Duffy et al also shows considerably better survival of node negative versus node positive breast cancers in 9040 patients with breast cancer from 1998 to 2003 in the east of England. ${ }^{28}$

\section{Strengths and limitations of study}

The nationwide registration in the Netherlands of breast cancer incidence, pathology, and treatment data by the Netherlands Cancer Registry, combined with linkage to the municipal administration for vital status verification, provides unique and reliable population based data. However, our study has some limitations. Owing to the nature of our research question, a large difference in follow-up existed between the two cohorts. In the supplementary table, follow-up for both cohorts was restricted to five years maximum to make comparison possible. However, changes in long term survival between the two cohorts might not be fully picked up at this time, because of the shorter follow-up time of the most recent cohort. Comparing 10 year and
15 year survival analyses of both time cohorts in the future will be informative. Furthermore, between 1999 and 2005, it was not standard of care in the Netherlands to evaluate hormone and HER2 status, making adjustment for these factors in our oldest cohort impossible. As our main interest was to identify and quantify the effect of traditional prognostic factors in the current era, we solved these limitations partly by analysing the two time cohorts separately. The 19992005 cohort gives insights on the effect on long term survival. Finally, although we have extensive clinicopathological data, no data were available on patients' comorbidity, which probably influences both primary outcome (survival) and type of treatment, and some influence on tumour stage and lymph node stage at detection cannot be excluded.

\section{Conclusion and policy implications}

In conclusion, our population-wide study in 173797 female patients is the first to use such recent data to assess the effect of traditional prognostic factors such as tumour size and nodal status on survival. Our results can aid both policy makers on national programmes and physicians in clinical decision making, as well as informing patients about the effect of stage and treatment choices on their prognosis. Furthermore, our data are of special importance for research trials that often use prognosis per tumour stage as primary outcomes. Tumour size and nodal status still had a significant and major influence independent of tumour biology in the current era of more conservative surgery and the new, more effective, and widely applied systemic (neo-) adjuvant therapies. Our results emphasise the importance of tumour stage at diagnosis of breast cancer, as it still greatly affects overall survival.

We thank the registration teams of the cancer centres for data collection and the scientific staff of the Netherlands Cancer Registry.

Contributors: MMAT-L and SSiesling designed the study. Data were collected by the registration teams under the supervision of SSiesling. SSaadatmand and RB did the statistical analyses. SSaadatmand and MMAT-L drafted the manuscript. All authors critically revised the manuscript for important intellectual content. SSaadatmand is the guarantor.

Funding: The Netherlands Cancer Registry is funded by the ministry of Health, Welfare, and Sport of the Netherlands. The funders had no role in the conduct of the study; collection, management, analysis, or interpretation of the data; or preparation, review, or approval of the manuscript.

Competing interests: All authors have completed the ICMJE uniform disclosure form at www.icmje.org/coi_disclosure.pdf (available on request from the corresponding author) and declare: no support from any organisation for the submitted work; no financial relationships with any organisations that might have an interest in the submitted work in the previous three years; no other relationships or activities that could appear to have influenced the submitted work.

Ethical approval: The study was approved by the privacy committee of the Netherlands Cancer Registry.

Transparency: The lead author (the manuscript's guarantor) affirms that the manuscript is an honest, accurate, and transparent account of the study being reported; that no important aspects of the study have been omitted; and that any discrepancies from the study as planned (and, if relevant, registered) have been explained.

Data sharing: Additional data are available from S Siesling at s.siesling@iknl.nl.

This is an Open Access article distributed in accordance with the Creative Commons Attribution Non Commercial (CC BY-NC 4.0) license, which permits others to distribute, remix, adapt, build upon this work 
non-commercially, and license their derivative works on different terms, provided the original work is properly cited and the use is non-commercial. See: http://creativecommons.org/licenses/ by-nc/4.0/.

1 Allemani C, Weir HK, Carreira H, et al. Global surveillance of cancer survival 1995-2009: analysis of individual data for 25,676,887 patients from 279 population-based registries in 67 countries (CONCORD-2). Lancet 2015;385:977-1010.

2 Siegel RL, Miller KD, Jemal A. Cancer statistics, 2015. CA Cancer J Clin 2015;65:5-29.

3 Cossetti RJ, Tyldesley SK, Speers CH, et al. Comparison of breast cancer recurrence and outcome patterns between patients treated from 1986 to 1992 and from 2004 to 2008. J Clin Oncol 2015;33:65-73.

4 DeSantis CE, Lin CC, Mariotto AB, et al. Cancer treatment and survivorship statistics, 2014. CA Cancer J Clin 2014;64:252-71.

5 Berry DA, Cronin KA, Plevritis SK, et al. Effect of screening and adjuvant therapy on mortality from breast cancer. N Engl I Med 2005;353:1784-92.

6 De Gelder R, Heijnsdijk EA, Fracheboud J, et al. The effects of population-based mammography screening starting between age 40 and 50 in the presence of adjuvant systemic therapy. Int J Cancer 2015;137:165-72.

7 Brekelmans CT, Tilanus-Linthorst MM, Seynaeve C, et al. Tumour characteristics, survival and prognostic factors of hereditary breast cancer from BRCA2-, BRCA1- and non-BRCA1/2 families as compared to sporadic breast cancer cases. Eur J Cancer 2007;43:867-76.

8 Colzani E, Liljegren A, Johansson AL, et al. Prognosis of patients with breast cancer: causes of death and effects of time since diagnosis, age, and tumor characteristics. J Clin Oncol 2011;29:4014-21.

9 De Boer M, van Dijck JA, Bult P, et al. Breast cancer prognosis and occult lymph node metastases, isolated tumor cells, and micrometastases. J Natl Cancer Inst 2010;102:410-25.

10 Tan LK, Giri D, Hummer AJ, et al. Occult axillary node metastases in breast cancer are prognostically significant: results in 368 node-negative patients with 20-year follow-up. J Clin Oncol 2008;26:1803-9.

11 Verbeek AL, Broeders MJ, National Evaluation Team for Breast Cancer Screening, National Expert and Training Centre for Breast Cancer Screening. Evaluation of the Netherlands breast cancer screening programme. Ann Oncol 2003;14:1203-5.

12 Mittendorf EA, Ballman KV, McCall LM, et al. Evaluation of the stage IB designation of the American Joint Committee on Cancer staging system in breast cancer. J Clin Oncol 2015;33:1119-27.

13 Roumen RM, Pijpers H], Thunnissen FB, et al. [Summary of the guideline 'Sentinel node biopsy in breast cancer.' Dutch Work Group 'Sentinel Node Biopsy for Breast Cancer']. Ned Tijdschr Geneeskd 2000;144:1864-7.
14 Ho VK, van der Heiden-van der Loo M, Rutgers EJ, et al. Implementation of sentinel node biopsy in breast cancer patients in the Netherlands. Eur / Cancer 2008;44:683-91.

15 Romond EH, Perez EA, Bryant J, et al. Trastuzumab plus adjuvant chemotherapy for operable HER2-positive breast cancer. N Engl / Med 2005;353:1673-84

16 Perez EA, Romond EH, Suman VJ, et al. Trastuzumab plus adjuvant chemotherapy for human epidermal growth factor receptor 2-positive breast cancer: planned joint analysis of overall survival from NSABP B-31 and NCCTG N9831. / Clin Oncol 2014:32:3744-52.

17 De Munck L, Schaapveld M, Siesling S, et al. Implementation of trastuzumab in conjunction with adjuvant chemotherapy in the treatment of non-metastatic breast cancer in the Netherlands. Breast Cancer Res Treat 2011:129:229-33.

18 Nationaal Borstkanker Overleg Nederland (NABON). Richtlijn behandeling van het mammacarcinoom 2005. www.oncoline.nl/ uploaded/FILES/mammacarcinoom/Richtlijn\%20Behandeling\%20 van\%20het\%20Mammacarcinoom\%20oktober\%202005.pdf.

19 Van Herk-Sukel MP, van de Poll-Franse LV, Creemers GJ, et al. Major changes in chemotherapy regimens administered to breast cancer patients during 2000-2008 in the Netherlands. Breast) 2013;19:394-401.

20 Moossdorff M, van Roozendaal LM, Strobbe LJ, et al. Maastricht Delphi consensus on event definitions for classification of recurrence in breast cancer research. J Natl Cancer Inst 2014;106(12).

21 Edge BD, Compton CC, Fritz AG, Greene FL, Trotti A (eds). AJCC cancer staging manual. 7th ed. Springer, 2009:345-76.

22 Rakha EA, El-Sayed ME, Lee AH, et al. Prognostic significance of Nottingham histologic grade in invasive breast carcinoma. J Clin Oncol 2008;26:3153-8

23 Hudis CA, Barlow WE, Costantino JP, et al. Proposal for standardized definitions for efficacy end points in adjuvant breast cancer trials: the STEEP system. J Clin Oncol 2007;25:2127-32.

24 Dickman PW, Sloggett A, Hills M, et al. Regression models for relative survival. Stat Med 2004:23:51-64

25 Cole TJ. Setting number of decimal places for reporting risk ratios: rule of four. BMJ 2015;350:h1845.

26 Central Bureau of Statistics Netherlands. Population; gender, age, marital status and region, January 1. 1999-2012. http://statline.cbs nl/Statweb/publication/?VW=T\&DM=SLNL\&PA=03759NED\&D1= 2\&D2 $=0-96 \& D 3=0 \& D 4=11-24 \& H D=150714$ $1157 \& H D R=T, G 3 \& S T B=G 2, G 1$.

27 Carter CL, Allen C, Henson DE. Relation of tumor size, lymph node status, and survival in 24,740 breast cancer cases. Cancer 1989;63:181-7.

28 Duffy SW, Smith RA, Yen AMF, Tabar L. Real and artificial controversies in breast cancer screening. Breast Cancer Manag 2013;2:519-28.

(c) BMJ Publishing Group Ltd 2015 